Hence the results obtained by using $\Omega$ and $\Omega_{1}$ respectively in (4) differ only by a factor, and the condition (4) applies equally well to the equation in the general form. This proves the theorem as stated.

The Lie theory gives no general method of finding the group of a given differential equation, and the problem of finding such a group is precisely the problem of finding $\xi$ and $\eta$, solutions of $(4)$.

If $\xi$ and $\eta$ are chosen in advance, the general form of the differential equation which can be integrated by their aid can be determined in precisely the same manner as in the Lie theory. Thus the Lie theory offers no formal aid in the solution of the above mentioned type of equation not furnished by this theorem.

However, there are some interesting considerations of a geometrical character due to Monge, Lie, and others which are suggestive occasionally; it is possible to restate some of these also, and the author proposes to do this in a later paper.

The method used in this paper can be applied to other types of differential equations, and Lie's essential results for those types obtained. These types will form the subject matter of another paper.

UNIVERSTTY OF MISSOURI, March 3, 1909.

\title{
HEATH'S EUCLID.
}

The Thirteen Books of Euclid's Elements Translated from the Text of Heiberg with Introduction and Commentary. By T. L. Heath, C.B., Sc.D. Cambridge, University Press, 1908. 8 vo. 3 volumes. \$13.50.

IT may properly be said of Dr. Heath's latest contribution to mathematical literature - and may it not be his last! - that it is characteristically British, and perhaps nothing better could be said of a work on the great mathematical classic of the world. We are tempted to think that England does not produce the great works of Germany, say in the history of mathematics as also in the theory of this science, and we point to Cantor and to Hankel, to Braunmühl and possibly to Günther, or even to Simon, as justifying this thought. And yet, when the English scholar does bring out a book, it is quite as when a British general takes possession of a conquered province - there is 
nothing more to say. What so scholarly work has appeared on early Greek geometry as Allman's, or where is there such a readable survey of Greek mathematics as a whole as is to be found in Gow? What elementary history of mathematics is so charmingly written as Ball, or what one has found its way into so many languages or has passed through so many editions?

And the same questions may be asked with respect to the ancient classics of mathematics - where may one go save to England? Heiberg's scholarly contributions? - yes, and the world is greatly the debtor of this indefatigible worker whose ability to read the medieval manuscripts of mathematical classics is probably not equaled among living scholars. But Heiberg is working on an entirely different problem, one of text criticism, of finding the probable form of the original, and of comparing the codices. When it comes to a thorough study of the mathematical side of the classics of Greece, the world must go to England. Paul Tannery might have done this kind of work if he had only had the time, although his great scholarship left. a monument built merely of fragments. But no continental writer has stayed with the problem with the tenacity of purpose that characterizes a Briton when he sets to work at his task, and hence it is to England that we must go for Diophantos, for Apollonius, for Archimedes, and for Euclid - to England where Greek is not yet dishonored, and where the classics in mathematics are still held in highest esteem.

But when we consider what scholars have made possible this appreciation of the works of the ancient masters, when we seek out the names of those who have followed in the footsteps of Billingsley and Wallis and Simson, we find ourselves possessed of doubt as to whether it is England after all that produces such works as these, for we find that it is one single scholar who has done it all. Cantor has written a monumental work, and Zeuthen has contributed worthily to the science, and the lamented Braunmühl has given us a helpful and scholarly treatise, and Loria has written with his usual brilliancy,- - but after all, it is the kind of work that Dr. Heath has done that makes the work of these other men possible. And so, whether it be the effect of English education, or British tenacity, or the individual writer, all who are interested in the history of mathematics should recognize their indebtedness and the indebtedness of education in general, to the man who has produced these works. 
Dr. Heath's Diophantos was published in 1885 , a single volume of 248 pages, and the first noteworthy modern treatment of the work of the father of Greek algebra. This was followed in 1896 by a volume on Apollonius of Perga, and this in 1897 by the works of Archimedes. And now, after more than ten years, and as a culmination of these contributions, comes the Euclid, a work that no one but an Englishman could write in the true con amore spirit, one that appeals more to English education than to that of any other country, and one that comes just at the time for bidding farewell, if such must be the case, in royal fashion to the text-book whose history it sets forth.

The purpose of the author is to give a new and better translation of Euclid's elements, to recite the history of the most important definitions and propositions, to set forth the criticisms and suggested improvements that have been offered from time to time, and, incidentally in appearance but designedly in fact, to show that, as compared with the great mass of modern textbooks, the Alexandrian classic stands like a mountain surrounded by foothills. The feelings of the author with respect to this supremacy of the work upon which he is writing appears in his opening quotation from De Morgan : "There never has been, and till we see it we never shall believe that there can be, a system of geometry worthy the name, which has any material departures (we do not speak of corrections or extensions or developments) from the plan laid down by Euclid." Perhaps it is a sufficient tribute to Dr. Heath's labors to say that few will be able to read his work without agreeing with him and with the illustrious predecessor whom he quotes.

A work of this nature is very welcome at this time in the development of education, and England is the natural place for its appearance. For not only has Euclid flourished on British soil as nowhere else, but English writers have left the field open by producing only text-books of Euclid rather than works showing a larger appreciation of his system. Therefore Dr. Heath sets for himself four tasks: (1) To make a new and more careful translation of the Elements, a labor that has not been attempted since Heiberg issued his scholarly Latin edition of the text, together with the Greek original, some twenty years ago ; (2) to include Books VII, VIII, IX, X, and XIII, with the so-called Book XIV in an appendix, none of these having appeared in English since Williamson's treatise of 1781-88; 
(3) to add such critical notes as should summarize the scientific discussion of all important definitions, postulates, and propositions, digesting such treatises as those of Schotten, $*$ Veronese, $\dagger$ and Engel and Stäckel; $\$$ (4) to embody also the results of the recent historical discussions of scholars like Tannery, Heiberg, Hankel, Bretschneider, Cantor, Loria, and Zeuthen.

The first volume is devoted to the Introduction, and to Books I and II of the Elements. The Introduction first discusses all that is positively known of the life of Euclid, and in this it adds nothing to our stock of knowledge, since no recent discoveries have thrown light upon the subject. It brings together in a few pages, however, the opinions of the early Greek writers and furnishes a good bibliography through which students can work. It then devotes one chapter to Euclid's other works; one to Greek commentators other than Proclus ; one to Proclus and his sources; one to the text and to a discussion of the manuscripts used by Heiberg, with a critical examination of the important question of possible alterations made by Theon; one to the scholia, in which the author accepts Heiberg's conclusion that all the lemmas are spurious and are largely due to the commentary of Pappus; one to Euclid in Arabia, and one to the nature of the Elements. It is well known that our knowledge of Euclid in the West, in the middle ages, came not from any Greek manuscripts or Latin translations, but from the Arabic. In his chapter on Euclid in Arabia the author has gathered a considerable amount of recent material and has made us his debtor by setting it forth in condensed form. He shows that if the Elements was not the first it was among the first of the books translated from the Greek into the Arabic, the earliest version being that of al-Hajjāj ben Yūsuf ben Matar, $\S$ who made two translations. It was next translated by Ishāq ben Hunain and this rendering was improved by Thābit ben Qurra (died 901). The third great translation was that of Nasiraddin at-Tūsī, $\|$ which was published in Rome in the Arabic in 1594, in reality a paraphrase of Euclid based on Arabic texts. From the Arabic the work got into Latin through the translation of

* Inhalt und Methode des planimetrischen Unterrichts, Leipzig, 1890.

† Fondamenti di geometria, Padova, 1891.

$\ddagger$ Die Theorie der Parallellinien von Euklid bis Gauss, Leipzig, 1895.

\& El-Hağğâă ben Jûsuf ben Mațar, to take Suter's transliteration. He lived under Hầrūn al-Rasīid and al-Māmūn, and therefore c. 786-835 A. D. He also translated the Almagest.

|| The Naṣ̂̂r-Ed-dîn el-Tâsî of Suter. He was born at Ṭūs in Kurāsān in 1201 and died in 1274 . 
Athelard of Bath (c. 1120) and the copy from it made by Campanus (c. 1250), or possibly, as Curtze thinks, from an earlier anonymous Latin version from which both Athelard and Campanus made their so-called translations. All of these standard texts Dr. Heath has compared with the Greek versions with a view to deciding upon the actual propositions originally in the Elements as they came from Euclid's hand. As is well known, the propositions deemed essential for plane geometry numbered probably 173 , the excess over the 167 of a book like Wentworth's being chiefly due to some semi-algebraic propositions of Book II. A list of the most important translations and editions follows the chapter on Euclid in Arabia.

The Introduction closes with a discussion of the nature of the Elements, probably the most important single chapter in whole work. The author shows with great clearness, and by reference to the treatise itself and to the ideas of the leading ancient commentators, exactly what are the distinctive features of Euclid's work. He refers to Proclus a statement to the effect that " in the whole of geometry there are certain leading theorems, bearing to those which follow the relation of a principle, all-pervading, and furnishing proofs of many properties. Such theorems are called by the name of elements; and their function may be compared to that of the letters of the alphabet in relation to language, letters being indeed called by the same

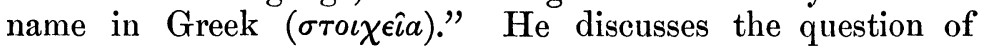
"Elements" prior to Euclid, by which the latter may have been influenced, and then considers the subject of " First principles," showing particularly the relation of Euclid's conception of what should be postulated to that of Aristotle and the followers of Plato. There is also in this chapter a very satisfactory treatment of the history of such topics as analysis and synthesis, and of such special forms of proof as the reductio ad absurdum. The chapter closes with a historico-philosophical discussion of the nature of definitions.

Ranking with the Introduction in point of interest is the treatment of Book I, since it is upon this book that geometry so largely depends. The history of such definitions as those of point, line, straight line, surface, plane, and angle, is here set forth with a clearness of style and a critical judgment that make the book a sine qua non to every writer upon geometry and to every one who seeks to train a teacher. The discussion of angle, for example, is a model of judicial treatment. It is 
not that of a man who holds a brief for Euclid, but one who recognizes that the Greek classic is not without defects and who seeks to remove any fair criticism by bettering the text. An idea of the thoroughness of the discussion may be derived from the fact that five large octavo pages are devoted to a much-condensed treatment of this particular concept. In the same spirit each definition, postulate, and axiom ("common notion") is discussed, both historically and philosophically, the weak features recognized, the strong ones pointed out, and the suggestions for improvement carefully considered. In particular the author recognizes, as everyone must, Euclid's failure in not introducing some kind of principle of continuity, say like one of those proposed by Killing, or some modification of Dedekind's postulate. The postulate of motion without deformation and the congruence postulates of Pasch, Veronese, and Hilbert, have also due recognition.

It cannot be expected that a reviewer should speak at length of the commentary, historical and mathematical, that follows. Each of the important propositions of the thirteen books is treated at more or less length, the proof and the possibilities of improvement being discussed. A spirit of fairness is everywhere apparent, and the reader lays down the third volume with the feeling that the work of a master has had masterly treatment. It will be generations before any one will again undertake this task, or will feel even tempted to do so. Riccardi* stated some years ago that no book save the Bible had been through so many editions as Euclid, and he listed over a thousand different publications of the Elements. Of the notable list now known, the editions of Heiberg and Heath will rank as the greatest for a long time to come.

The author is also deserving of special thanks for having placed an index and a glossary of Greek terms at the close of each of the three volumes. Typographically the work is up to the standard of the Cambridge University Press, and even the most critical will find little to condemn either in the subject matter or in the appearance of the work.

David Eugene Smith.

* Saggio di una bibliografia Euclidea, Bologna, 1887, pt. I, p. 3. 